\title{
SUBJETIVIDADES E JUVENTUDES CAMPESTRES: CONSTITUIÇÃO DE SENTIDOS SUBJETIVOS POR UM JOVEM DO CAMPO
}

\section{Subjectives and youth campestries: constitution of subjective senses by a rural youngster}

Leandro Bicalho Lopes - Universidade Federal de Viçosa/Brasil Lílian Perdigão Caixêta Reis - Universidade Federal de Viçosa/Brasil Sáhira Michele da Silva Celestino- Universidade Federal de Viçosa/Brasil

\begin{abstract}
RESUMO: Este estudo tem por objetivo analisar a constituição de sentidos subjetivos de jovens do campo acerca de si mesmo. Para tanto, adotou-se a epistemologia qualitativa de Gonzalez Rey e metodologia no modelo construtivo-interptretativo. Os instrumentos para construção da informação foram grupo focal, entrevista semiestruturada, e os mapas afetivos. Foram selecionados 11 (onze) participantes- jovens do campo da cidade de Cajuri-MG que estudam na zona urbana- sendo que se utilizou o estudo de caso de um deles. Assim, apoiados na perspectiva teórica dos sentidos subjetivos, os resultados revelaram uma concepção de juventude pautada na ideia de experimentação da vida ao mesmo tempo em que se considera a importância dos estudos nesse processo. As limitações impostas pela falta de acesso às políticas públicas e aos direitos sociais no campo fazem surgir sentimentos de inferioridade em relação a ele. Reflete-se ainda sobre a construção de projetos de vida destes jovens, pautados na cultura urbana, em busca do reconhecimento social, em detrimento a desvalorização social da cultura campestre, uma vez que, o modelo socialmente construído de jovem e juventude estão relacionados aos padrões da classe média urbana. Assim, a partipante acredita que a melhoria de vida está relacionada à migração para a zona urbana.
\end{abstract}

Palavras-chave: Campo. Juventude. Subjetividade

ABSTRACT: This study aims to analyze the constitution of subjective senses of young people on the field about themselves. To this end, we adopted Gonzalez Rey's qualitative epistemology and methodology in the constructive-interpretive model. The instruments for building information were based on focus group, semi-structured interview, and affective maps. Eleven (11) participants - rural youngsters who study in the urban area in the city of Cajuri, MG - were selected as the case study of one of them was used. Hence, supported by the theoretical perspective of the subjective senses, the results revealed a conception of youth based on the idea of experimentation of life while considering the importance of studies in this process. The limitations imposed by the lack of access to public policies and social rights in the countryside give rise to feelings of inferiority in relation to him/her. It is also reflected on the construction of life projects of these youngsters, based on urban culture in search of social recognition, to the detriment of the social devaluation of rural culture, since the socially constructed model of youth is related to the patterns of the urban middle class. Thus, the participant believes that the improvement of life is related to migration to the urban area.

Keywords: Field. Youth. Subjectivity

\section{INTRODUÇÃO}


Subjetividades e juventudes campestres: constituição de sentidos subjetivos por um jovem do campo

\subsection{Juventudes e as Juventudes do Campo}

Os estudos (OZELLA, 2003; BOCK, 2004 E 2007; OZELLA; AGUIAR, 2008; CÉSAR, 2008; CASTRO, 2005, 2009) que propõem analisar os jovens têm apontado para o domínio da utilização de uma concepção de juventude sob a ótica da perspectiva naturalizante, em que o jovem e o adolescente são vistos a partir da relação entre maturação biológica e psicológica. Assim, a puberdade demarcaria a entrada nessa fase de desenvolvimento, sendo a crise de identidade e a falta de responsabilidade suas principais características. Isso indica uma visão de adolescência que abarca somente o modelo hegemônico de juventude, pautado nos referenciais do modelo classe média.

Por outro lado, há perspectivas críticas a essa vertente dominante, como as defendidas por Ozella (2003), Bock (2004) e (2007), Ozella e Aguiar (2008), César (2008), que concebem a juventude como uma produção social, com características delimitadas em um determinado momento histórico, através das relações sociais e das formas de sobrevivência. Essas abordagens ressaltam a necessidade de se estudar os jovens enquanto atores sociais consubstanciados em realidades que os modificam e são modificadas por eles, substituindo a visão da juventude exclusivamente como etapa de passagem da infância para a vida adulta, por uma mais polissêmica. Consideram diferentes culturas e subjetividades demarcam distintas formas de se vivenciar a juventude, relacionando individualidade e influências socioculturais.

A juventude do campo se apresenta como uma realidade cujo contexto poderá demarcar diferentes formas de subjetivação quando comparada à juventude vivenciada nas cidades. Conforme mostra Carneiro (2007), há necessidade de uma leitura não dualista entre campo e cidade, já que estes diferentes universos se interpenetram - seja através da mídia, das novas tecnologias e das relações com o trabalho. No entanto, a autora afirma que não analisar as particularidades do mundo rural seria cair em reducionismo.

Tais particularidades passam tanto pela atração do jovem do campo pelo modo de vida urbano, considerado superior, quanto pelas limitações do alcance das políticas públicas para o público rural, principalmente os jovens (GALINDO 2014). Dessa forma, ser jovem no campo, um espaço que pode apresentar difíceis condições materiais e com pouco acesso às políticas públicas, é comumente conviver com a possibilidade de carregar a marca da invisibilidade e da exclusão social. 
A situação de desigualdade rural x urbano somado a atração dos jovens pelo modelo de juventude urbana, faz com que aumente o discurso sobre a migração como projeto de vida destes jovens, numa tentativa de melhoria de vida e reconhecimento social. A desvalorização da agricultura familiar; as relações autoritárias demarcadas na falta de autonomia principalmente da mulher, no seio da família; a educação escolar pautada na cultura urbana também são fatores que reforçam a aspiração da saída do campo (WEISHEIMER, 2005; FURLANI; BONFIM，2010; BRUMER，2007; ALVES; DAYRELL, 2015b; ZAGO, 2016).

Por outro lado (WHEISHEIMER, 2003; WANDERLEY, 2007; CARNEIRO, 2007 E 2008; CASTRO, 2009; COSTA; RALISCH 2013; LOPES; CARVALHO, 2015), também indicam a presença de um discurso entre os jovens que demonstra um desejo de ficar no meio rural, reafirmado por práticas que, segundo Carneiro (2007), combinam o trabalho na agricultura e em outros setores, como o comércio.

Neste trabalho, os termos juventude será privilegiado em detrimento ao de adolescência por compreender esse grupo como resultado de relações sociais produzidas no percurso da história (SILVA; LOPES, 2009).

\subsection{Subjetividade: uma perspectiva crítica}

A subjetividade será aqui tratada sob enfoque da psicologia histórico-cultural a partir da ideia de Gonzalez Rey. Nessa concepção, o sujeito é produto e produtor de sua realidade social, intersecionando sua história e a da sociedade na qual ele está inserido. A subjetividade nessa perspectiva aparece sob a lógica da superação da dicotomia entre objetivo/subjetivo, individual/social que caracteriza a psicologia tradicional, enfatizando que estes dois âmbitos estão em inter-relação sem se diluírem um no outro. Daí a sua complexidade, já que envolve fenômenos históricos, sociais, econômicos, culturais e processos individuais (GONZALEZ REY, 2005, 2011; LANE, 1994; AGUIAR et al. 2009).

Apesar deestarem imbricadas, para uma melhor explanação do conceito de subjetividade nessa perspectiva, Gonzalez Rey $(2005,2011)$ divide-a em subjetividade individual e subjetividade social. A primeira está relacionada ao sujeito concreto e suas formas psicológicas de funcionamento, atrelando a história de vida pessoal deste e sua relação com o meio. Ela corrobora com a ideia de que a subjetividade não é uma mera 
Subjetividades e juventudes campestres: constituição de sentidos subjetivos por um jovem do campo

reprodução do mundo social (TACCA; GONZALEZ REY, 2008). A segunda traz a ideia da cultura enquanto uma estrutura subjetiva produtora de subjetividades. Em outras palavras, a forma pela qual a subjetividade é gerada a partir do sistema cultural e se apresenta no nível social, não sendo nem externa e nem unicamente interna ao sujeito, já que ele a contém e faz parte dela (GONZALEZ REY, 2005).

É na unidade da confrontação entre subjetividade individual e subjetividade social que se configuram os sentidos subjetivos (GONZALEZ REY, 2005, 2011), conceito que será que será tratado no próximo tópico.

\subsection{Os Sentidos Subjetivos: um conceito chave}

Atrelado ao conceito de subjetividade tem-se a categoria sentido, construída por Vigotski e reelaborada por Gonzalez Rey, sob o conceito de sentido subjetivo, a qual foi amplamente utilizada por autores da psicologia social latino-americana (GONZALEZ REY, 2005, 2006, 2007, 2011; TACCA; REY, 2008; AGUIAR et al. 2009). Interrelacionado ao significado, o sentido, ou sentido subjetivo está vinculado à ideia de uma construção abstrata do real, relacionando a dialética objetividade/subjetividade nesse processo (AGUIAR et al. 2009).

Gonzalez Rey (2005) define sentido subjetivo como um processo simbólico e emocional resultado da experiência do sujeito, onde há uma interação desses processos atuais a anteriores e que vão definir a relação subjetiva do indivíduo com todas as coisas. As diferentes formas que o sujeito se colocará em um determinado contexto estão relacionadas ao sentido subjetivo dado às experiências em outros momentos e outras esferas da vida dele. Isso ocorre através da evocação de imagens que podem estar ligadas direta ou indiretamente à experiência atual e delas fazem surgir emoções que, por sua vez, evocam novas imagens, e assim sucessivamente, simbólico e emocional estão, neste caso, interligados (GONZALEZ REY, 2005, 2006, 2011). É o sentido subjetivo da complexa trama de vivências desse indivíduo que vai delimitar sua conduta e seus sentimentos nesse espaço. Esse processo só terá fundamentação se intercalado com a história social desse sujeito.

Mediante tais reflexões, o presente estudo, que é parte de uma dissertação de mestrado, problematizou a constituição de subjetividades dos jovens do campo, com o objetivo de analisar os sentidos subjetivos de um jovem do campo possui acerca de si mesmo. 


\section{MATERIAL E MÉTODO}

Adotou-se a perspectiva da epistemologia qualitativa, com análise construtivainterpretativa, propostas por Gonzalez Rey (2011). Este modelo qualitativo tem como fundamento a ideia de ciência como um processo construtivo - interpretativo, onde a interação entre pesquisador e sujeito pesquisado é que vai levar a construção das informações. Isso quer dizer um rompimento com a ideia de conhecimento como algo linear levando a um resultado único, para priorizar a existência de múltiplas possibilidades de entendimento para um mesmo público pesquisado. O pesquisador, assim, assume um papel ativo nesse processo. A importância do singular, também é uma característica marcante desta proposta, o que quer dizer a legitimação da qualidade da expressão do sujeito e não a quantidade, reforçando o estudo de caso como única posibilidade para o estudo da subjetividade (GONZALEZ REY, 2011).

Esse modelo qualitativo não prevê hipóteses a priori, mas essas vão surgindo a partir da construção de indicadores, que interpretados pelo pesquisador, ganham sentido no decorrer da pesquisa (GONZALES REY, 2011; CUNHA 2013). É a partir dos indicadores que se constroem as categorias que vão culminar na elaboração das zonas de sentido, que são uma junção de sentidos reunidos por semelhanças e afinidades (MARQUES, 2010; GONZALEZ REY, 2011; CUNHA 2013).

\subsection{Local do Estudo}

O estudo foi realizado no município de Cajuri-MG. A cidade possui um distrito, o Paraguai. A população total é de 4.047 habitantes, sendo 51,8\% urbana e 48,2\% rural. Estima-se que possui 500 jovens e 240 deles vivem no campo (CENSO, 2010). A escolha da cidade se deu pela experiência de trabalho prévio do pesquisador, no Centro de Referência de Assistência Social (CRAS), com o público local.

\subsection{Participantes da Pesquisa}

Os participantes foram jovens residentes na zona rural de Cajuri-MG, que cursam ensino médio na cidade sede. A faixa etária foi considerada de acordo com o Estatuto da Juventude (Lei $\mathrm{n}^{\mathrm{o}} 12.852$, de 5 de agosto de 2013), que preconiza a juventude entre a faixa etária dos 15 aos 29 anos, totalizando 11 participantes. 
Subjetividades e juventudes campestres: constituição de sentidos subjetivos por um jovem do campo

Foram selecionados, para o grupo focal, 11 participantes, respeitando o número médio (10 a 15) apontado por Trad (2009) para um bom funcionamento deste tipo de atividade. Todos com idade entre 15 e 17 anos. Somente 8 puderam participar das etapas seguintes- entrevista e mapas afetivos.

Para análise dos sentidos subjetivos foi escolhido um caso entre os 11 participantes, selecionado pela qualidade das informações para o presente trabalho. A participante será designada pelo nome fictício de Lorena.

\subsection{Instrumentos da Pesquisa e Análise das informações}

Os instrumentos utilizados na pesquisa foram grupo focal, aplicado ao grupo; entrevista semiestruturada, na modalidade oral, e os mapas afetivos (Bomfim, 2003), na modalidade escrita, aplicados individualmente.

Para construção das informações foi utilizada a da análise de conteúdo pautada em um processo construtivo-interpretativo (GONZALEZ REY, 2011). Sobre esse modelo de análise, Marques (2010) descreve as seguintes etapas: audição e leitura do material; demarcação de ênfases emocionais e temáticas; reconhecimento de indicadores de sentidos (diretos, indiretos e não relevantes); e por último, agrupamento dos indicadores em zonas de sentidos.

\section{RESULTADOS E DISCUSSÃO}

Este tópico aborda o plano das singularidades no sujeito estudado, utilizando-se das contribuições dos sentidos subjetivos para tal. O sujeito foi Lorena, de 17 anos. O quadro 1 a seguir mostra um panorama da construção das zonas de sentidos e seus indicadores a partir das informações da participante.

Quadro 1: Panorama da construção das zonas de sentidos 


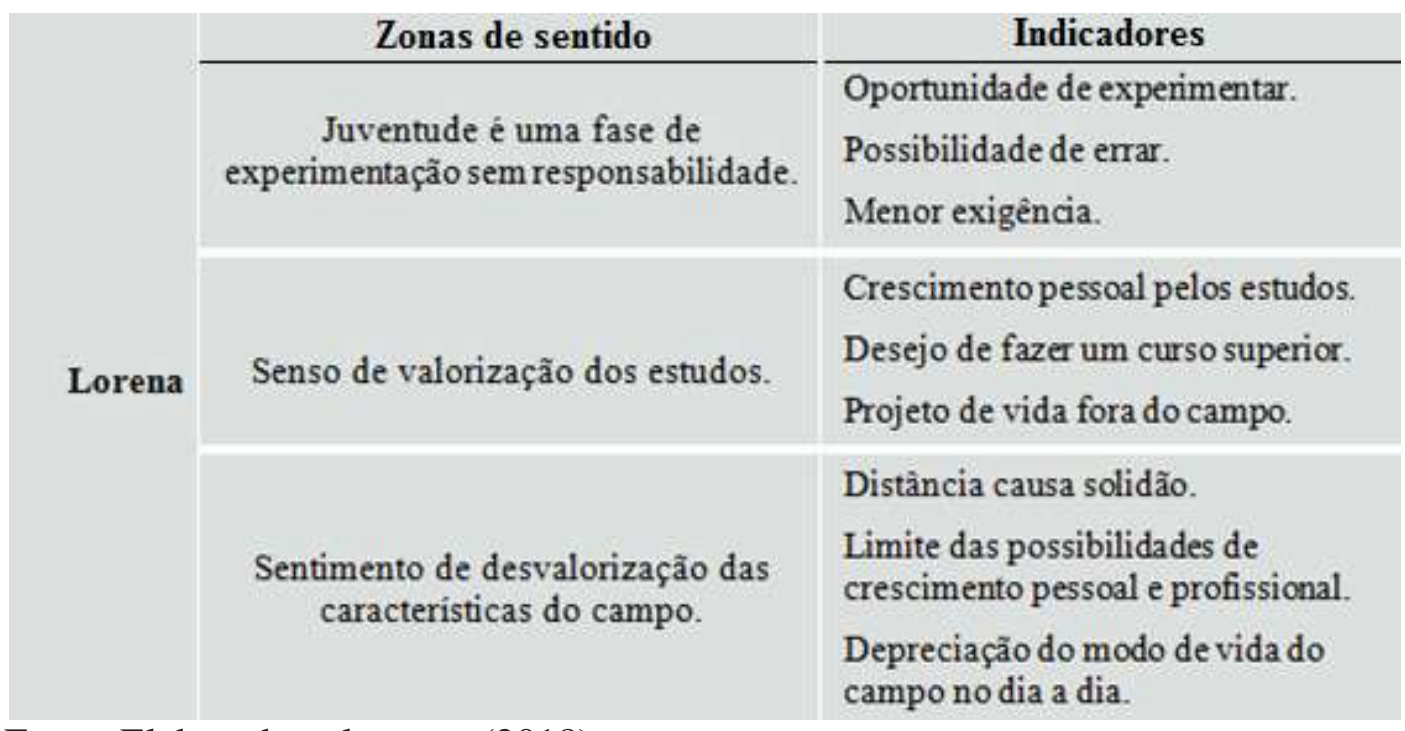

Fonte: Elaborado pelo autor (2018).

\subsection{A Solidão e as Dificuldades no Campo: Construções a Partir das Informações de Lorena}

Lorena possui 17 anos e é estudante no $2^{\circ}$ ano do ensino médio. Mora com os pais no campo desde que nasceu. A mãe trabalha como doméstica e também sempre morou lá, enquanto o pai, que é pedreiro e agricultor, nascido em uma pequena cidade do interior de Minas Gerais.

A participante disse ter começado a trabalhar aos oito anos de idade, como doméstica e na colheita do café: "Eu panho café desde nova, trabalho desde novinha desde oito, anos. Antes achava puxado, hoje até gosto". O Estatuto da Criança e do Adolescente (Lei 8.069 de 1990) proíbe que os menores de 14 anos de idade trabalhem, salvo na condição de aprendiz a partir dessa idade. Isso demonstra que Lorena necessitou desenvolver um senso de responsabilidade prematuro para sua idade na época. Entretanto, ela denota certa normalidade ao falar desta experiência, apontando que não é incomum este tipo de trabalho logo na infância.

Apesar, desta condição de labuta ainda criança na sua trajetória de vida, Lorena apresenta elementos de sentidos subjetivos próximos à visão hegemônica sobre o que é ser jovem pautada na ideia de um período de falta de compromisso. Para ela, ser adolescente é poder experimentar com um menor crivo da responsabilidade e uma menor exigência. Quando perguntada sobre o que é ser jovem, ela afirmou: "Igual eu acho que falei da última vez, você tem a oportunidade de experimentar e errar, poder errar pra aprender". Esteve presente, durante o contato com a participante, e reforçado na sua fala 
Subjetividades e juventudes campestres: constituição de sentidos subjetivos por um jovem do campo

anterior, certa incongruência entre a experiência das obrigações dela com o trabalho ainda criança, e a visão da juventude como uma etapa que exige menores compromissos.

De acordo com Tacca e Gonzalez Rey (2008) as concepções dominantes podem ser definidoras de sentidos subjetivos, limitando as opções da subjetivação no nível individual. Analisando essa relação entre concepções hegemônicas compartilhadas e singularidades, Santos (2010) traz uma importante contribuição sobre como o processo de singularização ocorre no sujeito. Segundo o autor, é no compartilhamento de uma visão coletiva que o sujeito produz o sentido, ou seja, "transforma o conhecimento entre os outros, simultaneamente, em conhecimento entre nós e para si” (SANTOS, 2010, p.119). Como esse procedimento não descarta a visão compartilhada, mas a torna mais complexa, o autor afirma que nesse movimento de produção de sentido, o indivíduo, ao incluir suas singularidades, também ocasiona sua própria inclusão histórica. As concepções hegemônicas sobre um determinado tema podem, então, levar a produção de vários sentidos subjetivos, conforme afirma Gonzalez Rey (2006, 2011), ao mesmo tempo os indivíduos podem configurá-las a partir de suas próprias experiências (necessidades, emoções, motivos) elaborando novos sentidos, sendo-os a chave para a construção da subjetividade.

Os pais de Lorena não supervalorizam os estudos e colocam o trabalho como um fator de grande importância em todas as épocas da vida. Quando foi perguntando para ela se os pais priorizam os estudos em detrimento ao trabalho, ela disse que eles: "querem que eu estude, mas querem que eu também continue trabalhando na roça". Não por acaso, Lorena gosta de trabalhar e de estudar. Contudo, seu projeto de vida, ainda que ambivalente, é "estar formada, trabalhando em outro lugar (...) bem longe, na cidade". Apesar de aprender o ofício da agricultura e gostar de fazê-lo, Lorena não planeja seguir os caminhos do pai nos afazeres do campo: “é, mas do meu futuro não quero isso não, até gosto, mas não pretendo ficar nisso, minha meta não é essa". Aqui também se pode perceber a importância das concepções hegemônicas sobre a ideia da ascensão social através dos estudos. A participante gosta e sabe realizar o serviço no campo, mas almeja um futuro com formação escolar superior e um trabalho longe da terra. Essas reflexões apontam tanto para elementos de sentidos subjetivos de desvalorização da agricultura quanto para os de enaltecimento da escolarização. Reforçando essa ideia ela diz: "na minha visão na lavoura não daria nenhuma melhoria crescimento pra mim". O campo assim, na visão dela, não apresenta perspectivas para o desenvolvimento profissional. 
Alves e Dayrell (2015b) apontam que os jovens do campo veem a migração como possiblidade de melhoria de vida e reconhecimento social. As possibilidades dessas conquistas no contexto rural são escassas, e os recursos financeiros advindos do trabalho na propriedade familiar rendem somente o suficiente para diversão aos finais de semana. Embora a maioria dos jovens do campo manifeste a vontade de permanecer no local de origem, grande parte deles acaba por vislumbrar somente a migração como forma para conquistar um trabalho e uma autonomia econômica (CASTRO, 2009).

O mapa afetivo de Lorena dá possibilidade de visualizar os sentimentos dela em relação ao campo.

Quadro 2: Mapa Afetivo de Lorena

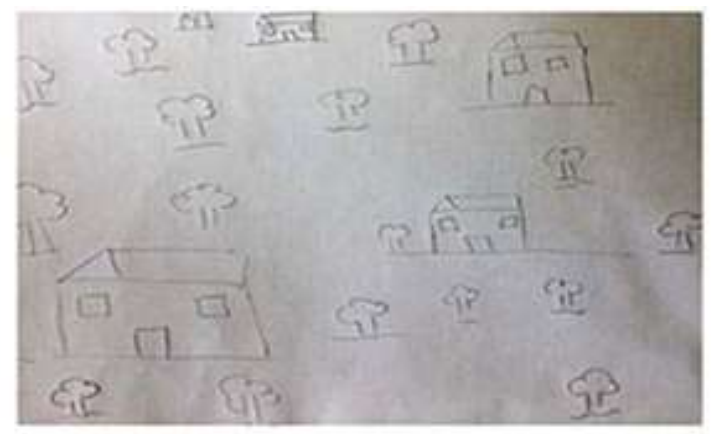

\begin{tabular}{|c|c|c|c|c|c|}
\hline Identificação & Estrutura & Significado & Qualidade & Sentimento & Metáfora \\
\hline $\begin{array}{c}\text { Lorena } \\
\text { Feminino } \\
17 \text { anos }\end{array}$ & $\begin{array}{c}\text { Cognitivo } \\
\text { e }\end{array}$ & $\begin{array}{c}\text { Distância } \\
\text { entreas casas }\end{array}$ & $\begin{array}{c}\text { Um lugar } \\
\text { tranquilo onde } \\
\text { mensino } \\
\text { médio } \\
\text { e as pessoas } \\
\text { um sabe quá }\end{array}$ & $\begin{array}{c}\text { Solidão } \\
\text { é o outro }\end{array}$ & Uma ilha \\
$\begin{array}{c}\text { Zona rural 2 } \\
17 \text { anos que } \\
\text { mora lá }\end{array}$ & & & & & \\
& & & & & \\
\hline
\end{tabular}

Sentido: Prevalece uma sensação de contraste, por um lado há afeto e segurança no lugar, mas por outro uma sensação de solidăo, diante do limitado número de amigos e vizinhos.

Diz que também é um lugar onde faltam trabalho e oportunidades de crescimento.

Fonte: Elaborado pelo autor (2018).

O mapa afetivo revela tanto literalmente quanto metaforicamente a distância entre as pessoas no local onde ela mora. Dessa forma, o sentimento apresentado em relação ao lugar é o de solidão, faltam amigos e pessoas próximas para conversar, o que a fez compará-lo com uma ilha, afastado de tudo.

Prevalece em Lorena um contraste entre a sensação de segurança que o lugar possui e as limitadas possibilidades de crescimento pessoal e profissional, bem como a distância entre as pessoas. 
Subjetividades e juventudes campestres: constituição de sentidos subjetivos por um jovem do campo

Assim, a participante diz que viver a juventude no campo é ter que lidar com uma série de dificuldades que o jovem da cidade não sofre: "é bem mais difícil, porque pra eu chegar aqui em Cajuri tenho que pegar duas conduções. Eu venho de Kombi até um certo lugar e depois pego ônibus". Demarca o longo percurso para chegar à escola, realizado por ela todos os dias, sendo que, caso necessitasse ficar na escola para alguma atividade no período da tarde, não seria possível.

Weisheimer (2005), em análise de pesquisas sobre a juventude rural, afirma que há uma situação de invisibilidade deste público, e as políticas públicas ainda têm um alcance restrito, já que desconsideram as singularidades de cada contexto, o que resulta em dificuldades de acesso à saúde, ao transporte e ao lazer (serviços socialmente necessários e garantidos pela constituição enquanto direitos sociais). Isso dificulta com que eles sejam reconhecidos enquanto sujeitos de direitos, culminando em uma retroalimentação entre invisibilidade e migração.

A visão pejorativa dada às características do campo, por Lorena, é também sentida pelo estigma que recebe nas relações interpessoais dentro da escola, poisela diz que as turmas do campo e da cidade não se misturam. Ao responder sobre como é a relação dentro da escola, disse: “[...] apelido geralmente não tem, mas sempre tem aquele que abusa, se acha melhor que a gente, por exemplo, eu e as meninas que vem da roça não somos de vir e conversar com outra turma (de Cajuri) e vice-versa".

A transição para o ensino médio e/ou ensino superior também é um fator que interfere na dinâmica da migração. Para Alves e Dayrell (2015b), nela, o jovem se dirige para as cidades que ofertam essa etapa da educação, e isso aparece como um fator de estigmatização da realidade rural. Vista pelo próprio jovem e pelos seus pais como instituição capaz de oferecer ascensão social, a escola produz e reproduz o estigma do jovem do campo através da homogeneização das características da juventude, pautada no modelo hegemônico de juventude classe média urbana (ALVES; DAYRELL, 2015b). Esse modelo de juventude difundido nas escolas é visto como culto e civilizado, contrapondo-se ao que difere dele, tido como irracional, ignorante e, nesse sentido, sob um discurso subliminar; portanto, o diferente é levado a querer se adaptar a esses padrões (ARROYO, 1982 apud ALVES; DAYRELL, 2015b). As novas experiências socioculturais, principalmente no ensino médio, são responsáveis por novas dinâmicas de desvalorização do espaço rural e pela atração por novos horizontes e novos projetos de vida (ZAGO, 2016; ALVES; DAYRELL, 2015a). 
Nesse sentido, valorizar o modo de vida campestre fica improvável, quando a depreciação é experienciada no dia a dia, limitando a possibilidade de constituição de novos sentidos subjetivos sobre o local, que lhe permita vê-lo de forma positiva.

\section{CONSIDERAÇÕES FINAIS}

O estudo apresenta a constituição de sentidos subjetivos de um jovem do campo acerca de si mesmo, favorecendo a compreensão de sua sujetividade e suas fomas de agir no mundo. Desta forma, os sentidos subjetivos construídos por Lorena se dão mediante as suas relações socais e a ausência de políticas públicas voltadas para a valorização do campo. Resultados estes encontrados por meio da entrevista e mapa afetivo realizado com o sujeito.

Lorena percebe a ausência de políticas públicas que favoreçam uma educação voltada para a cultura campestre em seu município, o que reforça o desvalor deste espaço. A necessidade de se locomover por meio de dois transportes para continuar os estudos também é característica marcante na realidade desta jovem. Essa dificuldade de acesso pode acarretar na evasão escolar de outros jovens que moram no campo. Além disso, as relações interpessoais na escola da zona urbana interferem no sentimento de inferioridade da Lorena e na dificuldade de se relacionar com outros grupos que não são originários da zona rural. Diante disso, o estudo sobre Lorena aponta o desejo de reconhecimento social e a melhoria de vida que, na visão dela, será alcançado através da migração.

Assim, esta investigação sucita a necessidade de se atentar para políticas públicas que atendam as diferenças socioculturais e econômicas da sociedade, para que favoreça a inclusão e o respeito às diferenças. Além disso, o desenvolvimento de políticas direcionadas aos jovens do espaço rural para que possam ter diretrizes na construção de seu projeto de vida, pautados na valorização da agricultura e do espaço local.

\section{REFERÊNCIAS BIBLIOGRÁFICAS}

AGUIAR, Wanda Maria Junqueira de. et al. Reflexões sobre sentido e significado. In: BOCK, Ana Mercês Bahia e GONÇALVES, Maria da Graça Marchina. A dimensão subjetiva da realidade: uma leitura sóciohistórica. São Paulo: Cortez, 2009. p.54-115.

ALVES, Maria Zenaide; DAYRELL, Juarez. Ser alguém na vida: um estudo sobre jovens do meio rural e seus projetos de vida. Educação e Pesquisa, São Paulo, v. 41, n. 2, p. 375-390, 2015a . Disponível em 
Subjetividades e juventudes campestres: constituição de sentidos subjetivos por um jovem do campo

http://www.scielo.br/scielo.php?script=sci_arttext\&pid=S1517-

97022015000200375\&lng=en\&nrm=iso. Acesso: 22 de Maio 2016

ALVES, Maria Zenaide; DAYRELL, Juarez. Transnacionalismo, juventude rural e a busca de reconhecimento. Educação e Pesquisa, São Paulo, v. 41, n. spe, p. 1455-1471, 2015b. Disponível em http://www.scielo.br/scielo.php?script=sci_artext\&pid=S15179702201500101455\&lng=en\&nrm=iso. Acesso: 23 de Maio 2016.

BOCK, Ana Mercês Bahia. A adolescência como construção social: estudo sobre livros destinados a pais e educadores. Psicologia Escolar e Educacional, Campinas, v. 11, n. 1, jan./jun. 2007, p. 63-76.

BOCK, Ana Mercês Bahia. A perspectiva histórica da subjetividade: uma exigência para la psicologia atual. Psicologia para América Latina, 2004. Disponível em: http://pepsic.bvsalud.org/scielo.php?script=sci_arttext\&pid=S187079350X2004000100002\&lng=pt\&nrm=iso Acesso: 11 de Jul. 2016.

BOMFIM, Zulmira Áurea Cruz. Cidade e afetividade: estima e construção dos mapas afetivos de Barcelona e de São Paulo. Tese (Doutorado em Psicologia) - Pontifícia Universidade Católica de São Paulo, São Paulo, 2003.

BRASIL. Lei n. 8.069 - 1990. Estatuto da criança e do adolescente. 2. ed. Brasília: Senado Federal, 1995. 171 p.

BRASIL. Lei $\mathbf{n}^{\mathbf{0}} \mathbf{1 2 . 8 5 2}$, de 05 de agosto de 2013. Institui o Estatuto da Juventude e dispõe sobre os direitos dos jovens, os princípios e diretrizes das políticas públicas de juventude e o Sistema Nacional da Juventude - SINAJUVE. Disponível em: http://www.planalto.gov.br/ccivil_03/_Ato2011-2014/2013/Lei/L12852.htm Acesso: 02 de jul. 2016.

BRUMER, Anita. A problemática dos jovens rurais na pós-modernidade. In: CARNEIRO, Maria José; CASTRO, Elisa Guaraná de (orgs.) Juventude rural em perspectiva. Rio de Janeiro: Mauad X, 2007. p. 35-52.

CARNEIRO, Maria José. "Rural" como categoria de pensamento. Revista Rurais, v.2, n. 1. Campinas, 2008, p.9-38.

CARNEIRO, Maria José. Juventude e Novas Mentalidade no Cenário Rural. In: CARNEIRO, Maria José \& CASTRO, Elisa Guaraná de (orgs.) Juventude rural em perspectiva. p. 53-66. Rio de Janeiro: Mauad X, 2007.

CASTRO, Elisa Guaraná de. Entre Ficar e Sair: uma etnografia da construção social da categoria jovem rural. Tese de Doutorado em Antropologia Social, Rio de Janeiro: UFRJ. 2005.

CASTRO, Elisa Guaraná de. Juventude Rural No Brasil: processos de exclusão e a construção de um ator político. Revista Latinoamericana de Ciencias Sociales, v. 7, n. 1, 2009, p. 179-208. 
CENSO DEMOGRÁFICO 2010. Características da população e dos domicílios: resultados do universo. Rio de Janeiro: IBGE, 2011. Disponível em: Acesso em 24 de Nov. de 2016.

CÉSAR, Maria Rita de Assis. A invenção da adolescência no discurso psicopedagógico. v 1. São Paulo: UNESP, 2008.

COSTA, Fernando Luís Martins; RALISH, Ricardo. A juventude rural do assentamento Florestan Fernandes no município de Florestópolis (PR). Revista de Economia e

Sociologia Rural. V.51. n. 3, 2013, p. 415-432. Disponível em: http://www.scielo.br/scielo.php?script=sci_arttext\&pid=S010320032013000300001\&lng=en\&nrm=iso. Acesso: 17 de maio 2016.

CUNHA, Carolina Novaes. Os sentidos subjetivos da participação política para pessoas com sofrimento mental. Dissertação de mestrado. Faculdade de Filosifia e Ciências Humandas. Universidade Federal de Minas Gerais, Belo Horizonte, 2013.

FURLANI, Daniela Dias; BOMFIM, Zulmira Áurea Cruz. Juventude e afetividade: tecendo projetos de vida pela construção dos mapas afetivos. Psicologia \& Sociedade; v. 22, n. 1, 2010, p. 50-59. Disponível em:

http://www.scielo.br/scielo.php?script=sci_arttext\&pid=S0102-

$71822010000100007 \& \operatorname{lng}=\mathrm{en} \& n r m=i s o \& t \operatorname{lng}=$ t. Acesso: 24 de Maio 2016.

GALINDO, Eryka. Em pauta: juventude rural e políticas públicas no Brasil. In:

MARILDA, A. de M.; STROPASOLAS, Valmir Luís; Barcellos, Sérgio Botton (Org.) Juventude rural e políticas públicas no Brasil. 1ed. Brasília: Presidência da República, v. 1, 2014, p. 122-132.

GONZALEZ REY, Fernando. As categorias de sentido, sentido pessoal e sentido subjetivo: sua evolução e diferenciação na teoria histórico-cultural. Psicologia da Educação. n.24, 2007, pp. 155-179. Disponível em:

http://pepsic.bvsalud.org/scielo.php?script=sci_arttext\&pid=S141469752007000100011\&lng=pt\&nrm=isso. Acesso: 07 de Jul. 2016.

GONZALEZ REY, Fernando. As representações sociais como produção subjetiva: seu impacto na hipertensão e no câncer. Psicologia, Teoria e Prática, São Paulo, v. 8, n.2, p.69-85, 2006. Disponível em:

http://pepsic.bvsalud.org/scielo.php?script=sci_arttext\&pid=S1516-

36872006000200005\&lng=pt\&nrm=iso. Acesso: 28 de Jul. 2016.

GONZALEZ REY, Fernando. Subjetividade e saúde: superando a clínica da patologia. São Paulo: Cortez, 2011.

GONZALEZ REY, Fernando. Sujeito e subjetividade: uma aproximação histórico cultural. São Paulo: Pioneira Thomson Learning, 2005.

LANE, Silva. A Psicologia Social e uma nova concepção de homem para a psicologia. In: LANE, Silva; CODO, Wanderley. Psicologia social: o homem em movimento. 12. ed. São Paulo: Brasiliense, 1994. p. 10-19. 
Subjetividades e juventudes campestres: constituição de sentidos subjetivos por um jovem do campo

LOPES, Leandro Gomes Reis; CARVALHO, Denis Barros de. Dinâmica temporal do assentamento e os projetos de vida da juventude rural. Revista Economia e Sociololgia Rural, Brasília, v. 53, n. 4, Dec. 2015 p. 571-588. Disponível em: http://www.scielo.br/scielo.php?script=sci_arttext\&pid=S010320032015000400571\&lng=en\&nrm=iso. Acesso: 13 de maio 2016.

MARQUES, Alice Farias de Araújo. Eu músico: configurações subjetivas a duas ou três vozes. 2010. Tese (Doutorado em Educação)-Universidade de Brasília, Brasília, 2010.

OZELLA, Sérgio. Adolescências Construídas: a visão da psicologia sócio-histórica. São Paulo: Cortez, 2003.

OZELLA, Sérgio; AGUIAR, Wanda Maria Junqueira de. Desmistificando a concepção de adolescência. Cadernos de Pesquisa, v. 38, n. 133, jan./abr. 2008, p. 97-125.

SANTOS, Gilberto Lima dos. Significados e sentidos dos direitos entre adolescentes de Salvador. Tese (Doutorado Psicologia)-Universidade Federal da Bahia, Bahia, 2010.

SILVA, Carla Regina; LOPES, Roseli Esquerdo. Adolescência e juventude: entre conceitos e políticas públicas. Cadernos de Terapia Ocupacional da UFSCar. V. 17(2), 2009. p. 87-106.

TACCA, Maria Carmen Villela Rosa; GONZALEZ REY, Fernando. Produção de sentido subjetivo: as singularidades dos alunos no processo de aprender. Psicologia, Ciência e Profissão. v. 28, n.1, 2008, pp.138-161. Disponível em: http://www.scielo.br/scielo.php?script=sci_arttext\&pid=S141498932008000100011\&lng=en\&nrm=iso. Acesso: 07 de Jul. 2016.

TRAD, Leny Bomfim. Grupos focais: conceitos, procedimentos e reflexões baseadas em experiências com o uso da técnica em pesquisas de saúde. Physis, Rio de Janeiro, v. 19, n. 3, 2009, p. 777-796. Disponível em:

http://www.scielo.br/scielo.php?script=sci_arttext\&pid=S0103-

73312009000300013\&lng=en\&nrm=iso. Acesso: 24 de nov. 2016.

WANDERLEY, Maria Nazareth. Jovens rurais de pequenos municípios de Pernambuco: que sonhos para o futuro. In: CARNEIRO, Maria José; CASTRO, Elisa Guaraná de (orgs.). Juventude rural em perspectiva. Rio de Janeiro: Mauad X, 2007. p.21-34.

WEISHEIMER, Nilson. Juventudes Rurais: Mapa de Estudos Recentes. Brasília: Ministério do Desenvolvimento Agrário, 2005.

ZAGO, Nadir. Migração rural-urbana, juventude e ensino superior. Revista Brasileira de Educação, Rio de Janeiro, v. 21, n. 64, Mar. 2016, p. 61-78. Disponível em: http://www.scielo.br/scielo.php?script=sci_arttext\&pid=S141324782016000100061\&ln $\mathrm{g}=\mathrm{en} \& \mathrm{nrm}=$ iso. Acesso: 01 de jun. 2016 


\section{Credenciais da/os autora/es}

LOPES, Leandro Bicalho. Graduado em bacharel em Psicologia (UNIVIÇOSA) e licenciatura em História (UFOP), Mestre em Economia Doméstica (UFV). E-mail: leandrobicalholopes@yahoo.com.br

REIS, Lílian Perdigão Caixêta. Professora na Universidade Federal de Viçosa, graduada em bacharel e licenciatura em Psicologia (PUC MINAS), Mestre em Família na Sociedade Contemporânea (UCSAL), Doutora em Psicologia do Desenvolvimento Humano (UFBA), Pós-Doutorado em Psicologia do Desenvolvimento Humano - PNPD Institucional (UFBA). E-mail: lilian.perdigao@ufv.br

CELESTINO, Sáhira Michele da Silva. Mestranda em Educação (UFV), graduada em licenciatura em Geografia (UFV), Pós-Graduação em Educação Especial e Inclusiva com Ênfase em Deficiências Múltiplas e Sensoriais (Faculdade Única de Ipatinga). Email: sahira.celestino@ufv.br

Endereço para correspondência: Leandro Bicalho Lopes. Rua dos Estudantes, n.200, apartamento 208, Centro, CEP: 36570-081, Viçosa/MG. E-mail:

leandrobicalholopes@yahoo.com.br

Como citar este artigo (Formato ABNT): LOPES, Leandro Bicalho; REIS, Lílian Perdigão Caixêta; CELESTINO, Sáhira Michele da Silva. Subjetividades e juventudes campestres: constituição de sentidos subjetivos por um jovem do campo. Educação, Psicologia e Interfaces, v. 3, n.3, p. 122-136, 2019. DOI: https://doi.org/10.37444/issn2594-5343.v3i3.172

Recebido: 07/08/2019.

Aceito: 20/11/2019. 